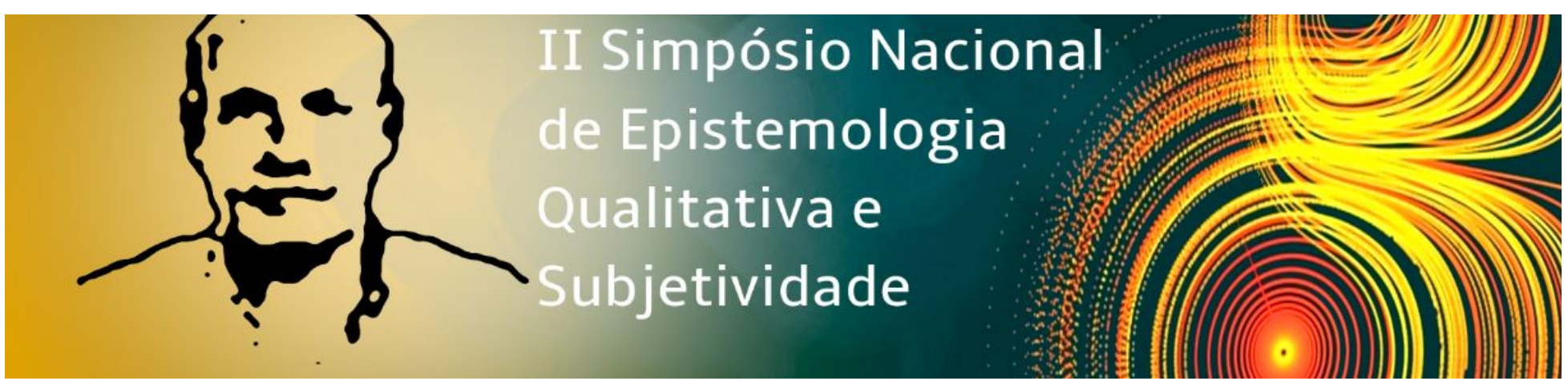

Eixo temático: A subjetividade na formação de professores e outros profissionais

\title{
Avaliação para as Aprendizagens nas Práticas Profissionais Aplicadas em Saúde: Ideias Iniciais e Desafios
}

Allana Resende Pimentel Calaça, Universidade de Brasília, allanarpc@gmail.com

\section{Resumo}

Esse trabalho se insere no contexto do desenvolvimento de meus estudos de mestrado. A questão central está relacionada com o processo de avaliação dos estudantes durante a sua inserção no espaço-tempo destinado ao Estágio Profissional Supervisionado, em uma escola técnica de saúde. Isto porque, estando o aprendiz posto em um ambiente repleto de possibilidades formadas em uma determinada cultura, o seu processo de aprendizagem e desenvolvimento profissional não se realiza à margem, mas se constrói nas relações sociais (GONZÁLEZ REY, 2005). Para González Rey e Mori (2011), a subjetividade social compõe os processos subjetivos do indivíduo, mas também pode contribuir para a produção de contradições que favorecem a produção e expressão de sentidos subjetivos, simplificando o seu posicionamento em relação às representações dominantes. A educação em saúde no Brasil, nas últimas três décadas, tem fomentado espaços de produção de conhecimento na educação profissional que contribuíram com o processo de sistematização de experiências educacionais e o desenvolvimento de alternativas pedagógicas favorecedoras da aprendizagem (BORGES, 2012). Nessa direção, o Centro de Educação Profissional - Escola Técnica de Planaltina (CEP-ETP) como uma escola pública, tem por missão promover educação profissional pública de qualidade por meio da integração de atividades de ensino, extensão e pesquisa na formação de jovens e adultos críticos e reflexivos, com conhecimentos técnicos, científicos e humanísticos, compromissados com o mundo do trabalho e com a busca de soluções criativas para a sustentabilidade humana. Sendo assim, nas ações pedagógicas desenvolvidas no âmbito do Estágio Profissional Supervisionado, o estudante problematiza situações reais no contexto do desenvolvimento de uma ação integradora 


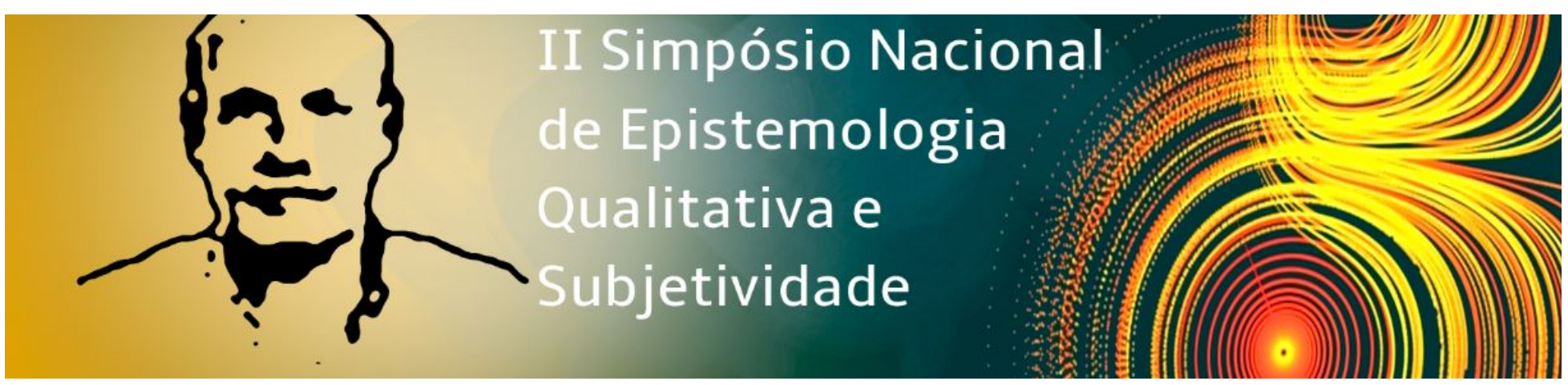

ensino-serviço, o que pode contribuir para a melhoria dos serviços de saúde prestados à comunidade. Neste caso, o Estágio Profissional Supervisionado pode favorecer a inserção do educando na complexidade dos diversos níveis de atenção à saúde que constitui um aspecto importante para o fortalecimento do Sistema Único de Saúde. Dessa forma, entendemos que as avaliações de aprendizagem, no contexto do Estágio Profissional Supervisionado em saúde, se desenvolvem em um cenário complexo, repleto de produções subjetivas, em que cada discente, cada contexto social e cada docente produz e expressa sentidos subjetivos a partir das experiências vivenciadas no âmbito do Estágio Profissional Supervisionado. Sendo assim, na visão do docente, como a subjetividade social e individual se integram no processo avaliativo que se desenvolve no contexto do Estágio Profissional Supervisionado?

Palavras chave: avaliação; subjetividade; educação em saúde.

\section{Referências}

BORGES, F.T.; GARBIN, C.A.S.G.; SIQUEIRA, C.E.; GARBIN, A.J.I.; ROCHA, N.B.; LOLLI, L.F.; MOIMAZ, S.A.S. Escolas Técnicas do SUS (ETSUS) no Brasil: regulação da integração ensino serviço e sustentabilidade administrativa. Ciência \& Saúde Coletiva, 17(4):977-987, 2012.

GONZÁLEZ REY, F. Pesquisa Qualitativa e Subjetividade: os processos de construção da informação. São Paulo: thomson learnig, 2005.

GONZÁLEZ REY, F.; MORI, V.D; Reflexões sobre o social e o individual na experiência do câncer. Psicologia \& Sociedade; 23(n. spe.), 99-108, 2011.

GONZÁLEZ REY, F. Subjetividade e Saúde: superando a clínica da patologia. São Paulo: Cortez, 2011.

MITJÁNS MARTÍNEZ, A.M; GONZÁLEZ REY, F.G. Psicologia, Educação e Aprendizagem Escolar: avançando na construção da leitura cultural-histórica. São Paulo, Ed. Cortez, 2017. 